\title{
Are cluster sets an effective method to induce muscular hypertrophy in response to resistance training?
}

\author{
Erick Carlos da Cunha Totóa ${ }^{\oplus}$, Miguel Soares Conceição ${ }^{\mathrm{b}} \oplus$, Amilton Vieira ${ }^{\mathrm{c}}$, Fernando Pareja-Blanco ${ }^{\mathrm{d}} \oplus$, Martim \\ Bottaroc $\bullet$, Daniel Boullosa ${ }^{\mathrm{e}, *}$
}

\section{Keywords:}

Strength training;

Set configuration;

Cross sectional area;

Muscle adaptations.
Palavras Chave:

Treinamento de força; Configuração de série; Área de corte transverso Adaptações musculares.

\begin{abstract}
There are a plethora of studies that have analyzed the effects of different resistance training methods on muscle hypertrophy. Recent studies have pointed out some potential advantage of training using cluster sets (CS) compared with traditional sets. It is still unclear whether CS are an effective method. The objective of this review was to investigate and discuss the current knowledge about the effect of CS on muscle hypertrophy. Four studies investigating the effect of CS on muscle hypertrophy were found. These studies demonstrated that CS induced similar or lower muscle hypertrophy than traditional sets. Thus, CS may lead to muscle hypertrophy, but did not provide a superior stimulus when compared to traditional sets of equated load.
\end{abstract}

\section{RESUMO}

Um conjunto de estudos que tem analisado o efeito de diferentes métodos de treinamento resistido na hipertrofia muscular. Estudos têm pontuado várias potenciais vantagens do treinamento usando séries em conglomerados (SC) quando comparado com séries tradicionais. Ainda não está claro se as SC é um método efetivo. O objetivo desta revisão foi investigar e discutir o conhecimento recente sobre o efeito das SC na hipertrofia muscular. Quatro estudos investigando o efeito das SC na hipertrofia muscular foram encontrados. Esses estudos demonstraram que as SC induziram similar ou menor hipertrofia muscular do que séries tradicionais. Portanto, as SC podem induzir hipertrofia, porém não fornecem um estímulo superior quando comparado às séries tradicionais com carga equiparada.

\section{RESUMEN}

Muchos estudios han analizado los efectos de diferentes métodos de entrenamiento de la fuerza en la hipertrofia muscular. Algunos estudios han resaltado las ventajas de introducir períodos de recuperación intra-serie (series cluster, SC) al compararlo con las series tradicionales. No está todavía claro si las SC son un método efectivo. El objetivo de esta revisión fue investigar y discutir el conocimiento actual sobre el efecto de las SC en la hipertrofia muscular. Se encontraron cuatro estudios investigando el efecto de las SC en la hipertrofia. Estos estudios demuestran que las SC inducen igual o menor hipertrofia que las series tradicionales. Así, las SC podrían inducir hipertrofia muscular pero no proporcionan un estímulo superior al compararlas con las series tradicionales.

\footnotetext{
a Academia Acuas Fitness, Brasília, DF, Brazil.

b Universidade de São Paulo, São Paulo, SP, Brazil.

' Universidade de Brasília, Brasília, DF, Brazil.

d Universidad Pablo Olavide, Sevilla, Espanha.

e INISA, Universidade Federal do Mato Grosso do Sul, Campo Grande, MS, Brasil.
}

\author{
*Autor correspondente: \\ Daniel Boullosa \\ E-mail: daniel.boullosa@gmail.com
}




\section{INTRODUCTION}

Skeletal muscle growth (i.e. muscle hypertrophy) is one of the most studied morphological adaptations in response to resistance training (RT) (Schoenfeld 2010). Muscular adaptations to RT are underpinned by the interaction among mechanical, hormonal, metabolic and neural stimuli. Several studies have manipulated the RT variables seeking for optimal hypertrophic responses. The RT variables such as the choice of exercise, exercise intensity (load), number of repetitions and sets performed, rest interval between sets and training frequency have received great attention from the scientific community in the last decades. Likewise, some advanced RT methods have been created and developed to potentiate strength training adaptations.

Among these methods, cluster sets (CS) have received special attention from the scientific community (Tufano, Brown et al. 2017). The CS method can be defined as a set that includes short periods of rest between individual repetitions or groups of repetitions (Tufano, Brown et al. 2017). By providing short rest periods, athletes are able to acutely attenuate fatigue, therefore attaining greater force, velocity and power in each repetition (Tufano, Conlon et al. 2016). In addition, studies have shown that the use of CS allows for a higher mechanical performance and training volume when compared with traditional set (TS) configuration (Haff, Whitley et al. 2003, Denton and Cronin 2006, Iglesias-Soler, Carballeira et al. 2014, Tufano, Conlon et al. 2016).

Increasing muscle mass is an important goal for athletes aspiring to maximize their muscle development. In this regard, it may be hypothesized that the superior mechanical stimuli induced by CS may lead to greater muscle hypertrophy when compared to TS. In addition, data from comprehensive (Figueiredo, de Salles et al. 2018) and meta-analytical (Krieger 2010, Schoenfeld, Ogborn et al. 2017) reviews support the notion of an increased training volume leading to superior muscle hypertrophy in a positive doseresponse fashion. Although CS has the potential to induce greater hypertrophic responses, the literature is scarce. Therefore, the purpose of this article was to review the current knowledge of the effect of the CS method on muscle hypertrophy. A second purpose of this review was to discuss the basis for further investigations.

\section{METHODS}

The following key words were used: "cluster sets", "set configuration", "intra-sets rest", "inter-repetition rest", "rest-pause". These words were combined with "resistance training", "strength training", "power training", "muscle hypertrophy", "muscle strength", "cross-sectional area", "muscle thickness", "muscle growth" and "lean body mass". Searches of PubMed and Google Scholar were conducted until April 2019. The reference lists of articles retrieved in the search were subsequently examined for any additional articles to be included. Only studies analyzing any muscle hypertrophy measure were included. The measures considered were muscle volume, cross-sectional area, muscle thickness, lean body mass and limb circumference.

The methodological quality of the found studies was evaluated with the PEDro scale for randomized controlled trials (de Morton 2009). The PEDro scale consists of 11 items, 10 of which assess aspects of the internal validity of the study. Every article was independently scored by two researchers.

\section{RESULTS}

Four studies comparing muscle hypertrophic measures of CS vs. TS were found (Table 1). These studies have demonstrated similar (Oliver, Jagim et al. 2013, Iglesias-Soler, Mayo et al. 2016, Arazi, Khanmohammadi et al. 2018) or lower (Goto, Ishii et al. 2005) hypertrophic effects of CS when compared with TS. Some heterogeneity of methodologies could be observed between studies. The heterogeneity between studies could be observed in samples' characteristics, duration of the study, different CS configuration, and muscle hypertrophy measures. The found studies scored low-to-moderate methodological quality.

\section{DISCUSSION}

The main aim of this review was to analyze the current knowledge on the effect of CS on muscle hypertrophy. To date, only four studies have investigated this topic. Three of these studies suggest a similar increases in muscle mass between CS and TS (Oliver, Jagim et al. 2013, Iglesias-Soler, Mayo et al. 2016, Arazi, Khanmohammadi et al. 2018), whereas only one study suggests that higher increases are observed in TS (Goto, Ishii et al. 2005).

The different methodological characteristics between the studies difficult further comparisons. These contradictory results may due to factors such as differences in techniques used to assess muscle hypertrophy, types of CS configuration, and training volume performed. Therefore, these possible factors will be discussed separately below.

\section{Measurement technique}

An important aspect to be discussed when analyzing the results of the studies citedabove, refers to the sensitivity of the technique used to measure changes in muscle mass. Of the four studies found, two used simple field measures of limb circumference (Iglesias-Soler, Mayo et al. 2016, 
Table 1. Studies comparing the effects of cluster sets (CS) with traditional sets (TS) on muscle hypertrophy.

\begin{tabular}{|c|c|c|c|c|c|c|c|}
\hline $\begin{array}{l}\text { Study } \\
\text { (year) }\end{array}$ & $\begin{array}{c}\text { Participants' } \\
\text { characteristics }\end{array}$ & Intervention & $\begin{array}{l}\text { Training } \\
\text { duration }\end{array}$ & $\begin{array}{c}\text { Work } \\
\text { volume }\end{array}$ & $\begin{array}{l}\text { Hypertrophy } \\
\text { measurement }\end{array}$ & Findings & $\begin{array}{l}\text { PEDro } \\
\text { score }\end{array}$ \\
\hline $\begin{array}{l}\text { Goto et } \\
\text { al. (2005) }\end{array}$ & $\begin{array}{c}\text { Young } \\
\text { untrained } \\
\text { men }(n=26)\end{array}$ & $\begin{array}{l}\text { TS group: } 4 \times 10,2 \text { min } \\
\text { of RI between sets. } \\
\text { CS group: } 4 \times 2 \times 5,30 \\
\text { and } 60 \text { s of RI between } \\
\text { repetitions and sets, } \\
\text { respectively. Load: } 10 \mathrm{RM}\end{array}$ & $\begin{array}{l}12 \text { weeks } \\
3 \times \text { week }\end{array}$ & Equated & $\begin{array}{c}\text { CSA of } \\
\text { quadriceps } \\
\text { muscle }\end{array}$ & $\begin{array}{c}\text { Greater increase (p } \\
<0.01 \text { ) in CSA in TS } \\
\text { group compared with } \\
\text { CS. }\end{array}$ & 5 \\
\hline $\begin{array}{l}\text { Oliver et } \\
\text { al. (2013) }\end{array}$ & $\begin{array}{l}\text { Young trained } \\
\text { men }(n=22)\end{array}$ & $\begin{array}{l}\text { TS group: } 4 \times 10,2 \mathrm{~min} \\
\text { of RI between sets. SC } \\
\text { group: } 4 \times 2 \times 5,60 \\
\text { S of RI between and } \\
\text { within sets. Load: } 60 \\
\text { to } 75 \% 1 \mathrm{RM}\end{array}$ & $\begin{array}{l}12 \text { weeks } \\
4 \times \text { week }\end{array}$ & Equated & $\begin{array}{c}\text { Total lean } \\
\text { body mass } \\
\text { (DEXA) }\end{array}$ & $\begin{array}{l}\text { Similar increase ( } p \\
=0.86 \text { ) in lean body } \\
\text { mass between TS } \\
\text { group (ES }=0.25 \text { ) and } \\
\text { CS group (ES }=0.14 \text { ). }\end{array}$ & 4 \\
\hline $\begin{array}{l}\text { Iglesias- } \\
\text { Soler et } \\
\text { al. (2015) }\end{array}$ & $\begin{array}{l}\text { Young trained } \\
\text { men and } \\
\text { women } \\
(n=13)\end{array}$ & $\begin{array}{l}\text { TS group: } 4 \times 10,3 \text { min } \\
\text { of RI between sets. CS } \\
\text { group: } 32,17.4 \text { sec of } \\
\text { RI between repetitions. } \\
\text { Load: } 10 \text { RM }\end{array}$ & $\begin{array}{l}5 \text { weeks } \\
2 \times \text { week }\end{array}$ & Equated & $\begin{array}{l}\text { Thigh } \\
\text { circumference } \\
\text { corrected } \\
\text { by skinfold } \\
\text { thickness }\end{array}$ & $\begin{array}{c}\text { Similar increase } \\
(P=0.38) \text { in thigh } \\
\text { circumference } \\
\text { between TS group (ES } \\
=0.35) \text { and CS group } \\
(E S=0.32) .\end{array}$ & 4 \\
\hline $\begin{array}{l}\text { Arazi et } \\
\text { al. (2017) }\end{array}$ & $\begin{array}{l}\text { Young } \\
\text { untrained } \\
\text { women } \\
(n=30)\end{array}$ & $\begin{array}{l}\text { TS group: } 4 \times 10,2 \\
\text { min of RI between } \\
\text { sets. CS group: } 4 \times 2 \\
\times 5,30 \text { and } 60 \text { s of RI } \\
\text { between repetitions } \\
\text { and sets, respectively. } \\
\text { Load: } 10 \mathrm{RM}\end{array}$ & $\begin{array}{l}5 \text { weeks } \\
3 \times \text { week }\end{array}$ & $\begin{array}{l}\text { Not } \\
\text { reported }\end{array}$ & $\begin{array}{l}\text { Arm and thigh } \\
\text { circumference }\end{array}$ & $\begin{array}{l}C S \text { group showed } \\
\text { slightly (ES }=0.34 \text { vs. } \\
0.17) \text {, not significant ( } p> \\
0.05) \text {, greater increase in } \\
\text { arm circumference. CS } \\
\text { and TS groups showed } \\
\text { similar increases in thigh } \\
\text { circumference ( } E S=0.19 \\
\text { vs. } 0.17 \text { respectively) }\end{array}$ & 5 \\
\hline
\end{tabular}

CSA: cross section area; RI: rest interval; DEXA: dual-energy x-ray absorptiometry; ES: effect size

Arazi, Khanmohammadi et al. 2018), one evaluated lean body mass via ddual-energy X-ray absorptiometry (DEXA) (Oliver, Jagim et al. 2013), and another evaluated changes in the cross-sectional area using magnetic resonance imaging (MRI) (Goto, Ishii et al. 2005). While studies using measures of circumference and DEXA suggest similar increases in muscle mass between CS and TS, the study using MRI suggests that TS may be superior for increases in muscle mass.

Muscle circumference is considered a raw measure of muscle hypertrophy, as changes in circumference may also be influenced by changes in body fluids and adipose tissue. Validation studies of equations using anthropometric data have found an estimation error between 1.7 to $1.6 \mathrm{~kg}$ (Martin, Spenst et al. 1990) and 2.2 to $2.8 \mathrm{~kg}$ (Lee, Wang et al. 2000). Therefore, the results of studies using anthropometry to estimate muscle mass may be limited in identifying small increases in muscle mass after RT. A previous study observed that lower limb muscle mass estimated from a DEXA measurement overestimated the MRIassessed muscle mass by $18 \%$ (Fuller, Hardingham et al. 1999). In addition, increases in lean body mass measured by DEXA may not correspond with increases in muscle mass measured by computed tomography, overestimating increases by $3.4 \%$ in thigh muscle mass in elderly individuals (Delmonico, Kostek et al. 2008). Noteworthy, in the study by Oliver et al. (2013), no attempt was made to estimate the amount of muscle mass through lean body mass data. Therefore, DEXA measurements of lean body mass may be less sensitive in the evaluation of small changes in muscle mass.

Interestingly, MRI has been used as a reference method for estimations of muscle mass in vivo. Estimation errors varyed from 1.2 to $1.3 \%$ when compared to cadaveric dissection (Beneke, Neuerburg et al. 1991). This technique may be preferable to other methods when measuring small changes in muscle mass. Thus, the only study using MRI reported higher increases in muscle mass after TS when compared to CS (12\% vs. 4\%) (Goto, Ishii et al. 2005). Hence, more studies are needed using more sensitive measures of muscle hypertrophy when investigating differences in muscle mass after a RT with CS configurations. 


\section{Cluster Set Structure}

Another important parameter to consider is the different CS structures used in every study. There are several ways in which CS can be structured. For example, additional intervals can be included within a set without changing the interval time between sets, thus increasing the total resting time. This set structure has been called basic CS (CSb). Alternatively, the resting time between sets can be redistributed within the sets between groups of repetitions ("intra-set rest") or between inter-repetitions ("inter-repetitions rest"), in order to create shorter and more frequent rest intervals (Tufano, Brown et al. 2017). With this approach, the total rest time between the protocols is equalized, which has been considered as a resting redistribution technique (RR) (Tufano, Brown et al. 2017). Recent research has investigated the effect of different types of CSb and RR on the acute physiological responses to $R T$, bringing important information about the effect of duration and frequency of interval on these responses.

In a previous study (Tufano, Conlon et al. 2019), the effects of different $\mathrm{CSb}$ and RR structures on the mechanical, metabolic, endocrine and rating of perceptual exertion (RPE) responses were analyzed. The protocols consisted of: CS4 $(3 \times 3 \times 4,30$ and $120 \mathrm{~s}$ of rest within and between sets), RR4 $(9 \times 4$, $52.5 \mathrm{~s}$ of rest between sets), and RR1 ( $36 \times 1,12 \mathrm{~s}$ of rest between repetitions). The intensity (75\%1RM), volume (36 repetitions) and total rest time ( $420 \mathrm{~s}$ ) were identical between protocols. The results revealed that there were no differences in the kinematic responses between protocols. However, velocity loss was lower during RR1 compared with RR4 ( $p=0.032$ ). In addition, similar hormonal, metabolic and RPE responses were observed between groups (Tufano, Conlon et al. 2019). The authors concluded that both CSb and RR can be used to preserve the quality of repetitions while stimulating anabolic processes associated with muscle hypertrophy.

Recent studies compared the mechanical and metabolic responses between different CSb structures and TS. García-Ramos et al. (2017) analyzed the acute response to different set configurations in the bench press exercise: TS1: $3 \times 10$, TS2: $6 \times 5$, CS5: $3 \times 10(5$ $\mathrm{s}$ inter-repetition rest), CS10: $3 \times 10$ (10 s), and CS15: $3 \times 10$ (15 s). The number of repetitions (30), interset rest $(5 \mathrm{~min})$, and relative intensity (10RM) were the same for all set configurations. Based on velocity loss induced during the set, set configurations were ranked as follows: TS1 (39.3\%), CS5 (20.2\%), CS10 (12.9\%), TS2 (10.3\%), and CS15 (10.0\%). Based on blood lactate concentration, set configurations were ranked as follows: TS1 $\left(7.9 \mathrm{mmol} \cdot \mathrm{L}^{-1}\right), \mathrm{CS} 5\left(5.8 \mathrm{mmol} \cdot \mathrm{L}^{-1}\right), \mathrm{TS} 2(4.2$ $\left.\mathrm{mmol} \cdot \mathrm{L}^{-1}\right), \mathrm{CS} 10\left(3.5 \mathrm{mmol} \cdot \mathrm{L}^{-1}\right)$ and CS15 $\left(3.4 \mathrm{mmol} \cdot \mathrm{L}^{-1}\right)$. These findings support the use of TS2, CS10, and CS15 to preserve the quality of the mechanical outputs, while CL10 and CL15 produce less metabolic stress than TS2. Similar results were observed in the study performed by González-Hernández et al. (2017), which showed that the inclusion of $10 \mathrm{~s}$ of rest intervals between repetitions with 10RM load in squat exercise, preserved the decrease in mechanical performance (velocity loss and vertical jump) while producing greater metabolic stress $\left(6 \mathrm{mmol} \cdot \mathrm{L}^{-1}\right)$.

Taken together, these findings indicate that the redistribution of the total rest interval to create shorter intervals $(10 \mathrm{~s})$ and more frequent pauses (inter-repetition rest), may be preferable strategies when the objective is the maintenance of the quality of the repetitions, while still offering stimuli for the development of muscular hypertrophy, mainly by the increase of the metabolic stress.

All the chronic studies found in this review used RR protocols, with volume, intensity and total rest time equalized between groups, but with different durations and frequency of rest intervals. Three studies used long (30 to $60 \mathrm{~s}$ ) and less frequent (intra-set) rest intervals (Goto, Ishii et al. 2005, Oliver, Jagim et al. 2013, Arazi, Khanmohammadi et al. 2018), whereas only one study used short (17.4 s) and more frequent inter-repetition rest intervals (Iglesias-Soler, Mayo et al. 2016). Interestingly, the study using longer and less frequent intervals indicated that TS may be superior to CS for increases in muscle mass (Goto, Ishii et al. 2005), whereas studies using shorter and more frequent rest intervals indicated that similar responses can be observed between TS and CS (Oliver, Jagim et al. 2013, Iglesias-Soler, Mayo et al. 2016, Arazi, Khanmohammadi et al. 2018). Therefore, more studies are needed investigating the effect of different manipulations of CS and RR on hypertrophic responses to RT.

\section{Training Volume}

As previously mentioned, exercise volume has been considered a key variable for muscle mass development. A dose-response relationship between total training volume and muscle hypertrophy has been suggested in the literature (Krieger 2010, Schoenfeld, Ogborn et al. 2017). One of the most relevant aspects of CS is that this type of set configuration allows athletes to achieve higher total training volume by performing more repetitions when using the same absolute load (Iglesias-Soler, Carballeira et al. 2014), or by lifting heavier absolute loads for a given number of repetitions (Iglesias, Boullosa et al. 2010). 
Iglesias-Soler (2014) showed that, when trained individuals performed parallel squat exercise with a 4RM load until muscle failure using either TS $(3 \times 4 R M$, $180 \mathrm{~s}$ rest between sets) or CS (36 s rest between each individual repetition), the maximum number of repetitions performed was significantly higher for CS compared to TS (45 vs. 9 repetitions, respectively). Subsequently, Garcia-Ramos et al. (2016) showed that the inclusion of a short rest interval between the individual repetitions ( $6 \mathrm{~s}$ ) was enough to increase the total training volume (more repetitions per set), while maintaining the quality of training (greater power output) during six sets of parallel squats using loads between 50 and $80 \% 1$ RM.

In the study by Denton \& Cronin (2006), 9 strengthtrained men performed 3 randomized experimental RT sessions using TS ( $4 \times 6 \mathrm{RM}, 300 \mathrm{~s}$ rest between sets), CS with equalized volume $(8 \times 3,130 \mathrm{~s}$ rest every three repetitions), or CS equalized only by the total rest time. In the latter group, the loading regime was similar to the CS group with equalized volume, but additional repetitions were allowed in the $2^{\text {nd }}, 4^{\text {th }}, 6^{\text {th }}$ and $8^{\text {th }}$ sets, which were performed until muscle failure. The results showed that the number of repetitions completed was significantly higher for the CS group with sets to failure when compared to the TS and CS groups with equalized volume ( 30 vs. 23.6 vs. 24 respectively). These additional repetitions resulted in significantly greater total work and blood lactate concentrations.

Previously, Iglesias et al. (2010) showed that CS allows the accomplishment of higher number of repetitions in the curl biceps and bench press exercises with a load of $70 \%$ and $90 \%$ of 1 RM. More recently, Tufano et al. (2017) investigated the effects of intra-set rest frequency and training load on acute mechanical responses in squat exercise, comparing 3 different set structures: TS $(3 \times 12$ with $60 \% 1 \mathrm{RM}), \mathrm{CS} 4(3 \times$ $3 \times 4$ with $75 \% 1 \mathrm{RM})$, and CS2 $(3 \times 6 \times 2$ with $80 \%$ $1 \mathrm{RM})$. The authors showed that, after 36 repetitions of the squat exercise, higher force, mechanical work and time under tension were attained in both CS structures when compared to TS. Therefore, CS allows more absolute load to be lifted for a given number of repetitions, thus increasing mechanical work, time under tension and metabolic stress, factors known to be involved in the anabolic responses to RT (Goto, Ishii et al. 2005, Dankel, Jessee et al. 2017).

These results suggest that CS structure may be an alternative method to traditional strength- or hypertrophy-oriented training by increasing training load without increasing exercise-induced fatigue. However, most studies found in this review equalized the volume and intensity of training between CS and
TS configurations. Thus, such studies do not take advantage of this potential benefit of CS.

\section{CONCLUSIONS}

The results of the current review suggest that CS methods are efficient for inducing increases in muscle mass, however, TS could be better situated under equalized total volume conditions. Further studies are warranted investigating the great potential of CS for muscle hypertrophy as it allows a higher training volume than TS for the same absolute load, or by lifting heavier absolute loads for a given number of repetitions. Additionally, it can be suggested the use of more sensitive measurement techniques (e.g, MRI, CT scan, ultrasound) to evaluate the hypertrophic potential of CS in further studies. Finally, studies in trained populations and elderly individuals are necessary to identify the hypertrophic and functional effect of different CS configurations.

\section{REFERENCES}

Arazi, H., A. Khanmohammadi, A. Asadi and G. G. Haff (2018). "The effect of resistance training set configuration on strength, power, and hormonal adaptation in female volleyball players." Appl Physiol Nutr Metab 43(2): 154-164.

Beneke, R., J. Neuerburg and K. Bohndorf (1991). "Muscle crosssection measurement by magnetic resonance imaging." Eur J Appl Physiol Occup Physiol 63(6): 424-429.

Dankel, S. J., M. B. Jessee, K. T. Mattocks, J. G. Mouser, B. R. Counts, S. L. Buckner and J. P. Loenneke (2017). "Training to Fatigue: The Answer for Standardization When Assessing Muscle Hypertrophy?" Sports Med 47(6): 1021-1027.

de Morton, N. A. J. A. J. o. P. (2009). "The PEDro scale is a valid measure of the methodological quality of clinical trials: a demographic study." 55(2): 129-133.

Delmonico, M. J., M. C. Kostek, J. Johns, B. F. Hurley and J. M. Conway (2008). "Can dual energy X-ray absorptiometry provide a valid assessment of changes in thigh muscle mass with strength training in older adults?" Eur J Clin Nutr 62(12): 1372-1378.

Denton, J. and J. B. Cronin (2006). "Kinematic, kinetic, and blood lactate profiles of continuous and intraset rest loading schemes." J Strength Cond Res 20(3): 528-534.

Figueiredo, V. C., B. F. de Salles and G. S. Trajano (2018). "Volume for Muscle Hypertrophy and Health Outcomes: The Most Effective Variable in Resistance Training." Sports Med 48(3): 499-505.

Fuller, N. J., C. R. Hardingham, M. Graves, N. Screaton, A. K. Dixon, L. C. Ward and M. Elia (1999). "Assessment of limb muscle and adipose tissue by dual-energy X-ray absorptiometry using magnetic resonance imaging for comparison." Int J Obes Relat Metab Disord 23(12): 1295-1302.

Garcia-Ramos, A., J. M. Gonzalez-Hernandez, E. Banos-Pelegrin, A. Castano-Zambudio, F. Capelo-Ramirez, D. Boullosa, G. G. Haff and P. Jimenez-Reyes (2017). "Mechanical and Metabolic Responses to Traditional and Cluster Set Configurations in the Bench Press Exercise." J Strength Cond Res. 
García-Ramos, A., V. Nebot, P. Padial, T. Valverde-Esteve, A. PablosMonzó and B. Feriche (2016). "Effects of short inter-repetition rest periods on power output lossess during the half squat exercise." Isokinetics and Exercise Science 24(4): 323-330.

Gonzalez-Hernadez, J. M., A. Garcia-Ramos, F. CapeloRamirez, A. Castano-Zambudio, G. Marquez, D. Boullosa and P. Jimenez-Reyes (2017). "Mechanical, metabolic, and perceptual acute responses to different set configurations in full squat." J Strength Cond Res.

Goto, K., N. Ishii, T. Kizuka and K. Takamatsu (2005). "The impact of metabolic stress on hormonal responses and muscular adaptations." Med Sci Sports Exerc 37(6): 955-963.

Haff, G. G., A. Whitley, L. B. McCoy, H. S. O'Bryant, J. L. Kilgore, E. E. Haff, K. Pierce and M. H. Stone (2003). "Effects of different set configurations on barbell velocity and displacement during a clean pull." J Strength Cond Res 17(1): 95-103.

Iglesias-Soler, E., E. Carballeira, T. Sanchez-Otero, X. Mayo and M. Fernandez-del-Olmo (2014). "Performance of maximum number of repetitions with cluster-set configuration." Int J Sports Physiol Perform 9(4): 637-642.

Iglesias-Soler, E., X. Mayo, D. Rio-Rodriguez, E. Carballeira, J. Farinas and M. Fernandez-Del-Olmo (2016). "Interrepetition rest training and traditional set configuration produce similar strength gains without cortical adaptations." J Sports Sci 34(15): 1473-1484.

Iglesias, E., D. A. Boullosa, X. Dopico and E. Carballeira (2010). "Analysis of factors that influence the maximum number of repetitions in two upper-body resistance exercises: curl biceps and bench press." J Strength Cond Res 24(6): 1566-1572.

Krieger, J. W. (2010). "Single vs. multiple sets of resistance exercise for muscle hypertrophy: a meta-analysis." J Strength Cond Res 24(4): 1150-1159.

Lee, R. C., Z. Wang, M. Heo, R. Ross, I. Janssen and S. B. Heymsfield (2000). "Total-body skeletal muscle mass: development and cross-validation of anthropometric prediction models." Am J Clin Nutr 72(3): 796-803.
Martin, A. D., L. F. Spenst, D. T. Drinkwater and J. P. Clarys (1990). "Anthropometric estimation of muscle mass in men." Med Sci Sports Exerc 22(5): 729-733.

Oliver, J. M., A. R. Jagim, A. C. Sanchez, M. A. Mardock, K. A. Kelly, H. J. Meredith, G. L. Smith, M. Greenwood, J. L. Parker, S. E. Riechman, J. D. Fluckey, S. F. Crouse and R. B. Kreider (2013). "Greater gains in strength and power with intraset rest intervals in hypertrophic training." J Strength Cond Res 27(11): 3116-3131.

Schoenfeld, B. J. (2010). "The mechanisms of muscle hypertrophy and their application to resistance training." J Strength Cond Res 24(10): 2857-2872.

Schoenfeld, B. J., D. Ogborn and J. W. Krieger (2017). “Doseresponse relationship between weekly resistance training volume and increases in muscle mass: A systematic review and meta-analysis." J Sports Sci 35(11): 1073-1082.

Spiering, B. A., W. J. Kraemer, J. M. Anderson, L. E. Armstrong, B. C. Nindl, J. S. Volek and C. M. Maresh (2008). "Resistance exercise biology: manipulation of resistance exercise programme variables determines the responses of cellular and molecular signalling pathways." Sports Med 38(7): 527-540.

Tufano, J. J., L. E. Brown and G. G. Haff (2017). "Theoretical and Practical Aspects of Different Cluster Set Structures: A Systematic Review." J Strength Cond Res 31(3): 848-867.

Tufano, J. J., J. A. Conlon, S. Nimphius, L. E. Brown, H. G. Banyard, B. D. Williamson, L. G. Bishop, A. J. Hopper and G. G. Haff (2017). "Cluster Sets: Permitting Greater Mechanical Stress Without Decreasing Relative Velocity." Int J Sports Physiol Perform 12(4): 463-469.

Tufano, J. J., J. A. Conlon, S. Nimphius, L. E. Brown, L. B. Seitz, B. D. Williamson and G. G. Haff (2016). "Maintenance of Velocity and Power With Cluster Sets During High-Volume Back Squats." Int J Sports Physiol Perform 11(7): 885-892.

Tufano, J. J., J. A. Conlon, S. Nimphius, J. M. Oliver, A. Kreutzer and G. G. Haff (2019). "Different Cluster Sets Result in Similar Metabolic, Endocrine, and Perceptual Responses in Trained Men." J Strength Cond Res 33(2): 346-354. 